\title{
The Use of Proteomics to Dissect the Molecular Specificities of T Cells in Type 1 Diabetes
}

\author{
Nadine L. Dudek*, Kailin Giam and Anthony W. Purcell
}

Department of Biochemistry and Molecular Biology, Monash University, Australia

\begin{abstract}
Presentation of peptides derived from beta cell proteins to autoreactive lymphocytes is critical for the development and progression of type 1 diabetes. How tolerance to beta cell antigens is broken is yet to be fully elucidated. The high metabolic demand on beta cells, the high concentration of granule proteins and the susceptibility of islets to cellular stress may all contribute to the presentation of abnormal ligands in the pancreas. Evidence for nonconventional presentation of peptide ligands and post-translational modification of peptides to $T$ cells has emerged in both human studies and animal models of diabetes. Challenges in identifying targets of autoimmunity are being increasingly met by advances in modern mass spectrometry. Here we review recent advances in mass spectrometry and their application to studies of peptides involved in immune recognition in diabetes.
\end{abstract}

Keywords: Insulin secretory granule; Antigen processing; T cell epitope; SWATH-MS

\section{Introduction}

Type 1 diabetes (T1D) is characterized by the autoimmune mediated destruction of insulin secreting beta cells. The ensuing deregulation of glucose homeostasis leads to hyperglycemia and a range of complications that manifest even in the presence of exogenous insulin administration. It is one of the most common organ-specific autoimmune diseases diagnosed in young children and the incidence of disease is increasing for reasons that are not well understood. It is clear that a complex interplay of both environmental and genetic factors contribute to the development of T1D [1,2]. Environmental influences may include viral infections, parasitic infections, dietary challenges and colonization with microbes, either commensal or pathogenic. Recently there has been great interest in the role of the gut microbiome in influencing susceptibility or resistance to many disease states, including autoimmune disease [3-7]. The composition of the microbiome is in turn intimately linked with both the environment and the genetic makeup of the host. In humans, a number of genes have been associated with T1D including CTLA4 [8,9], PTPN22 [10], IL2RA [11] and the variable number of tandem repeat polymorphism in the promoter region of the insulin gene $[12,13]$. In the non-obese diabetic (NOD) mouse, a well studied murine model of T1D, over 20 insulin-dependent diabetes $(I d d)$ intervals or genes associated with susceptibility to disease have been mapped [14]. However, of the genes that predispose to this disease in humans and in murine models, the strongest contributing factor is the genotype of an individual's major histocompatibility (MHC) molecules. Between $50-60 \%$ of the familial clustering seen in T1D can be attributed to allelic variation in the human leukocyte antigen (HLA) genes encoding classical class I and II MHC proteins [15-17].

MHC molecules present peptides derived from the degradation of intracellular or extracellular proteins. Hundreds of thousands of different HLA-bound peptides (the immunopeptidome) are displayed on the cell surface for scrutiny by passing T cells. HLA alleles and their gene products are frequently associated with resistance to disease due to pathogen driven genetic diversification of the MHC region. However the polymorphism that drives antigen specificity is also linked to selective presentation of self-peptides, leading to autoimmune diseases such as T1D. Indeed the strong association of certain HLA molecules with T1D has led to the hypothesis that isletderived peptides are presented differentially by disease associated and non-associated alleles. As such, much work has focused on identifying the peptides presented by class I and class II MHC molecules to CD8 and $\mathrm{CD} 4^{+} \mathrm{T}$ cells respectively. Although a range of different immune cells are required for the development of diabetes, both $\mathrm{CD} 4^{+}$and $\mathrm{CD} 8^{+}$ $\mathrm{T}$ cells are key players in the initiation and effector phases of T1D [18]. The outcome of $\mathrm{T}$ cell engagement with peptide/MHC complexes is dependent on a myriad of factors including $\mathrm{T}$ cell receptor affinity, peptide-MHC affinity, T cell frequency, co-stimulation, the site at which the interaction occurs and the cell type on which the MHC molecule is expressed. Identification of ligands presented by MHC class I and II molecules does not explain how autoreactive $\mathrm{T}$ cells escape tolerance induction and become activated in the periphery per se. However an emerging theme in autoimmune disease is that presentation of peptides in non-classical conformations or bearing post-translational modifications (PTMs) at the site of tissue damage have a key role in the disease process

\section{The Insulin Secretory Granule as a Source of Autoanti- gens}

A number of the proteins targeted by the immune response during the development of T1D are associated with components of the insulin secretory granule. Although the precise mechanisms by which these proteins become targeted remain to be elucidated, it has been hypothesized that the high metabolic demand on pancreatic islets and the high concentration of secretory proteins at the site of release contributes to aberrant processing and presentation of granule proteins, leading to the demise of the beta cell. The best studied of

${ }^{*}$ Corresponding author: Nadine L. Dudek, Department of Biochemistry and Molecular Biology, Monash University, Clayton, Victoria 3800, Australia, Tel: +61399051557; E-mail: nadine.dudek@monash.edu

Received June 11, 2013; Accepted July 15, 2013; Published July 21, 2013

Citation: Dudek NL, Giam K, Purcell AW (2013) The Use of Proteomics to Dissect the Molecular Specificities of T Cells in Type 1 Diabetes. J Diabetes Metab S12 006. doi:10.4172/2155-6156.S12-006

Copyright: $\odot 2013$ Dudek NL, et al. This is an open-access article distributed under the terms of the Creative Commons Attribution License, which permits unrestricted use, distribution, and reproduction in any medium, provided the original author and source are credited. 
these granule proteins is insulin, the major component of the secretory granule produced by pancreatic beta cells. There is substantial evidence in both mice and humans to implicate proinsulin as a dominant antigen in T1D. In humans, autoantibodies against insulin are a major risk factor for the development of T1D and are the earliest markers of islet autoimmunity in at-risk children [19,20]. Protection against diabetes is associated with the level of insulin mRNA transcripts expressed in the thymus by way of a variable number of tandem repeats (VNTR) upstream of the human proinsulin gene. It is hypothesized that lower thymic expression of proinsulin in individuals carrying the class I VNTR allele allows autoreactive T cells to escape thymic deletion and move to the periphery $[12,21,22]$. This is supported by murine studies, in which thymic overexpression of proinsulin is protective [23] and graded expression of proinsulin in the thymus of NOD mice shows a dose-dependent, inverse correlation with peripheral $\mathrm{T}$ cell responses to proinsulin [24].

Insulin is compacted into dense core secretory vesicles, produced by budding at the trans-golgi network. Immature granules, enveloped by the membranes of the golgi, mature during their progression to the plasma membrane. During this process, acidification within the lumen allows aggregation of soluble proteins and promotes retention within the vesicle [25-27]. The change in $\mathrm{pH}$ activates prohormone convertases, which cleave proinsulin to insulin [28]. As changes in metabolic demand may exceed the rate at which new insulin molecules can be synthesized, the beta cell stores insulin within mature cytoplasmic insulin secretory granules that are released by exocytosis. Release of insulin granules is regulated by nutrient status, hormonal and neuronal factors; however it is glucose-stimulation that is the principal mechanism of insulin secretion, triggered by an increase in intracellular calcium levels. During normal cellular function, the contents of the secretory granule are transiently exposed to the immune system, making them prime candidates as initiating antigens. Recently, two other secretory granule proteins, Chromogranin A and islet amyloid polypeptide (IAPP) have been identified as targets of autoreactive T cells in NOD mice $[29,30]$. Like insulin, both proteins are synthesized as larger precursor molecules and require post-translational processing within the secretory granule. Chromogranin A is a neuroendocrine secretory protein, and as such is not expressed exclusively in beta cells. The natural cleavage product WE14 is however recognized by a family of well-characterized CD4 ${ }^{+} \mathrm{T}$ cell clones isolated from the islets of NOD mice, including the BDC2.5 $\mathrm{T}$ cell clone [29]. The same group also identified a sequence from IAPP as the target of another highly diabetogenic T cell clone [30]. IAPP is expressed exclusively in the beta cells and is co-secreted with insulin. Responses to IAPP have also been reported in human patients with T1D $[31,32]$. Interestingly IAPP has a tendency to form aggregates and has been shown to form amyloid deposits in patients with in type 2 diabetes, which is preceded by the formation of toxic IAPP oligomers [33]. Following the identification of IAPP as a target in NOD mice, Delong et al. hypothesized that similar aggregates of IAPP could form during inflammatory stress in T1D [30]. They propose that such aggregates may be processed by antigen-presenting cells to form neoepitopes capable of triggering autoreactive cells.

It seems reasonable to suggest that other components of the secretory granule will be added to the expanding list of proteins targeted during the development of T1D (reviewed in $[34,35]$ ). Indeed immune responses to a number of proteins involved in the production and regulation of the secretory granule such as the zinc transport family member 8 [36], IA-2 and IA-2 $\beta[37,38]$ are well established. Due to the role of deregulated glucose homeostasis in both type 1 and type 2 diabetes, a number of proteomic studies have been conducted to characterize the insulin granule proteomes [39-41]. The most recent of these by Schvartz et al. [41] utilized a series of density gradients to separate immature from mature insulin secretory granules, the latter of which have higher density. Stable isotope labeling with amino acids in cell culture (SILAC) was used to examine the enrichment or absence of proteins in immature versus mature granules by mass spectrometry. This produced a list of 140 proteins enriched in mature secretory granules including insulin, chromogranins, secretogranins and members of the vSNARE complex required for effective secretion. A large number of additional proteins shared between secretory granules and other organelles were also identified. In our own analysis of MHC class I bound proteins purified from in vitro cultured beta cells, we have sequenced peptides from many of these secretory granule proteins [42], not surprisingly demonstrating the intersection of the class I processing pathway with components of the secretory granule. Characterization of the proteins involved in the biogenesis and exocytosis of insulin secretory granules will undoubtedly reveal novel antigens targeted during the development of T1D. However the main challenge becomes determining which of these is relevant to disease.

\section{Non-classical Presentation and Post-translational Modification of Peptide Ligands}

The mechanisms by which $\mathrm{T}$ cell tolerance is broken during the development of T1D are likely to be complex, and it is not only proteins within the secretory granule that are targeted during the disease. However recent studies have highlighted the potential role of posttranslational modifications and non-conventional peptide presentation in the development of diabetes, evidence which comes largely from the granule proteins insulin and Chromogranin A. Mohan et al. [43,44] demonstrated non-conventional interactions in the recognition of a major epitope in the insulin B chain spanning amino acids 9-23. Two sets of islet infiltrating $\mathrm{CD} 4^{+} \mathrm{T}$ cells, designated Type A and Type B, display differential recognition of peptide MHC complexes generated by interaction with free peptides or denatured protein versus processing of whole native protein. Type A cells recognize insulin presented by antigen presenting cells with the $\mathrm{B}_{9.23}$ peptides presented in a standard peptide binding register. Type $B$ cells react only with antigen presenting cells fed with soluble $B$ chain peptide and not with native insulin protein. In the case of Type B cells, the peptide is recognized in a binding register that is shifted by a single amino acid. The recognition of insulin presented in this non-conventional manner by Type B T cells is thought to result from the uptake of secretory granules containing degradation products of insulin by antigen presenting cells tightly associated with blood vessels in the islets. It is hypothesized that these non-conventional peptide-MHC complexes are only presented in the target tissue and not in the thymus, allowing Type $\mathrm{B}$ insulin reactive cells to escape thymic deletion and become activated in the periphery.

Altering peptide binding can provide a means of manipulating the immune response. Michels et al. utilized small molecules to target different regions of the MHC class II binding cleft to either inhibit or enhance $\mathrm{T}$ cell stimulatory capacity of the insulin $\mathrm{B}_{9-23}$ epitope in NOD mice [45]. We have also examined the ability of small molecules to alter $\mathrm{T}$ cell recognition in the setting of drug-induced hypersensitivity [46]. Abacavir is an antiretroviral drug used to treat HIV-I infection that in some cases induces severe cutaneous hypersensitivity reactions. This reaction is strongly associated with HLA-B ${ }^{\star} 57: 01$ but not closely related alleles $[47,48]$. We recently demonstrated perturbation of the HLA- ${ }^{\star} 57: 01$ peptide repertoire in the presence of abacavir using mass spectrometric analysis of HLA-bound peptides [46]. The alteration in the repertoire was due to the specific and non-covalent interaction 
of abacavir with HLA-B ${ }^{\star} 57: 01$, binding in a region that surrounded the $\mathrm{F}$ pocket of the antigen binding cleft. The dramatic change in the repertoire of peptides selected and presented in the presence of abacavir facilitates the robust activation of a broad range of $\mathrm{T}$ cell clonotypes against "altered self". The immune response to abacavir-exposed antigen presenting cells resembles allograft rejection in magnitude and severity, highlighting potential risks associated with using small molecule modulators of peptide binding to treat autoimmune disorders. A tantalizing possibility combines the observations that small molecules can modulate determinant selection of MHC molecules and the potential of circulating metabolites derived from certain gut microbes to also demonstrate this functionality. Although no microbial metabolite has been observed to bind to conventional MHC class I or class II molecules and alter peptide binding we have recently shown that MAIT cells, a dominant $\mathrm{T}$ cell population in the gut, recognize bacterial Vitamin B metabolites in complex with the non-classical HLA molecule MR1 [49]. That the interaction of a small molecule with a single pocket of the antigen binding cleft can have such a dramatic impact on peptide presentation and $\mathrm{T}$ cell activation raises the possibility that this is an important mechanism in the development of autoimmunity.

Non-classical presentation has also been demonstrated for the recently identified autoantigen Chromogranin A. The natural cleavage product of Chromogranin A, WE14, was stimulatory for a number of $\mathrm{CD} 4^{+} \mathrm{T}$ cell clones, including BDC2.5 at high peptide concentrations [29]. The carboxyl terminus of the WE14 peptide appears to interact with $\mathrm{I}-\mathrm{A}^{\mathrm{g} 7}$ outside the normal binding groove and lacks the $\mathrm{N}$-terminal amino acids that would occupy positions 1 and 4 of the cleft, anchors which are usually important for stable MHC binding. Truncation of C-terminal amino acids of the WE14 peptide reduced MHC binding and $\mathrm{T}$ cell stimulatory capacity, highlighting the importance of the flanking residues lying outside the binding groove. A second product of Chromogranin A spanning amino acids 29-42 (vasostatin 1) was also found to be recognized by the BDC2.5 $\mathrm{T}$ cell clone [50]. This peptide had higher stimulatory capacity, requiring much lower peptide concentrations than WE14. However the immunogenicity of the WE14 peptide is greatly increased by treatment with tissue transglutaminase. This enzyme catalyzes the deamidation of glutamine and asparagine residues, in addition to forming isopeptide bonds between the side chain amine of lysine and the side chain carboxyl groups of either glutamate or aspartate residues. This suggests the true target of BDC2.5 T cells is a post-translationally modified Chromogranin A peptide possibly containing a crosslink facilitated by transglutaminase mediated isopeptide bond.

Evidence of post-translational modification of autoantigens in T1D also comes from a $\mathrm{T}$ cell epitope within the insulin $\mathrm{A}$ chain. Mannering et al. demonstrated that a spontaneous modification of adjacent cysteine residues in the insulin $\mathrm{A}$ chain is essential for $\mathrm{T}$ cell recognition [51]. The formation of a vicinal disulphide bond in this $\mathrm{A}$ chain epitope is not a native disulfide configuration, suggesting that it may form from misfolded insulin or during antigen processing. Posttranslational modification of peptide ligands is an emerging theme in the development of disease. For example citrullination of arginine residues have been implicated in the pathogenesis of rheumatoid arthritis and multiple sclerosis and deamidation of gluten peptides in celiac disease generates higher affinity, more immunogenic HLA DQrestricted $\mathrm{T}$ cell epitopes $[52,53]$. In general we observe up to $5 \%$ of naturally eluted peptides purified from MHC molecules and sequenced by LC-MS/MS bear post-translational modifications; including $\mathrm{N}$-terminal acetylation, pyroglutamate formation and deamidation.
The frequencies of some common modifications identified in the immunopeptidome of the human pancreatic cell line 11B4 are shown in figure 1 (manuscript in preparation). Although PTMs are presented as part of the normal peptide repertoire, PTMs may have a number of influences on antigen presentation and not only generate novel immunogenic peptides, but may also affect the specificity of proteolytic cleavage and change the affinity of the peptide for binding to MHC.

\section{Advances in Mass Spectrometry for the Identification of PTMs}

Mass spectrometry can be used to definitively identify and characterize PTMs in biological samples. However the complexity of the immunopeptidome, the potentially low abundance of disease relevant ligands and compounding factors such as register shifting and non-canonical acquisition of peptides present some significant technical hurdles. For example, we have shown using in vitro cultured murine beta cells, that a key immunodominant epitope of islet-specificglucose-6-phosphatase catalytic subunit related protein (IGRP), an important target in NOD mice, may be presented at as low as one $\mathrm{MHC} /$ peptide complex per cell [42]. However, several advances in mass spectrometry make identifying relevant peptides from primary beta cells or beta cell lines a more achievable goal.

Multiple reactions monitoring (MRM) is the first of these advances (Figure 2). MRM can be used for the detection and quantitation of analytes within a complex sample [54,55]. While it has been used for a number of years for the analysis of metabolites and proteins, it is only recently that it has been employed for the detection and quantitation of MHC bound ligands [42,56-58]. MRM combines knowledge of the mass of the targeted peptide with diagnostic fragmentation information to provide highly sensitive and specific detection of peptides of interest. MRM analysis can be combined with an isotopically labeled internal peptide standard to allow absolute quantitation within the sample. From our experience, we find MRM analysis provides a

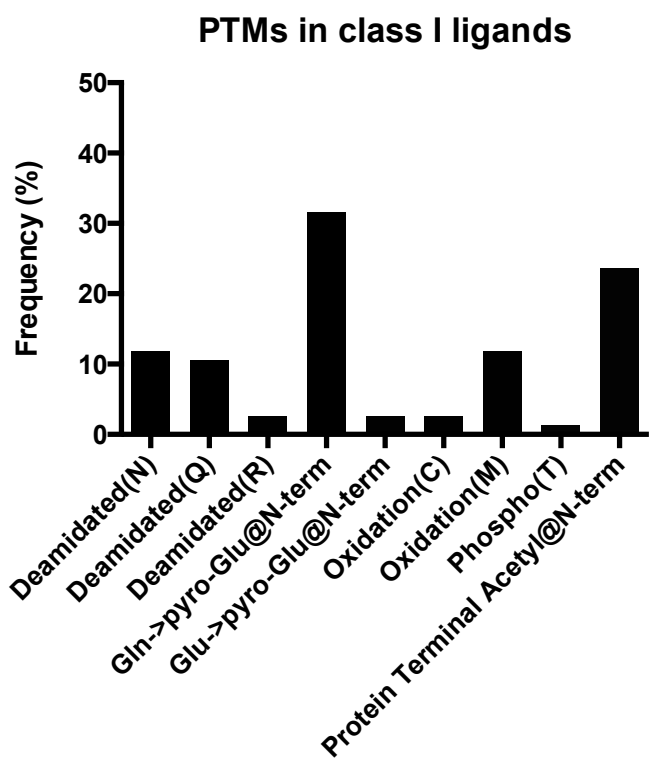

Figure 1: Peptide modifications identified in MHC class I ligands eluted from the human beta cell line 11B4. Modifications are shown as a percentage of total modified peptides (total number of peptides 2170,77 containing a posttranslational modification). 
500-fold increase in sensitivity compared with standard LC-MS/MS experiments. This provides an obvious advantage when looking for low abundance species. One of the most important applications for MRM analysis is the ability to analyze a large number of peptides in a single sample. In our hands we have monitored for up to 200 peptides in a single sample, this number can theoretically be increased into the thousands. The ability to screen for so many peptides also allows the inclusion of in silico-designed predictions. For example, it is possible to include a native peptide sequence of interest and a range of potential modifications predicted based on the amino acid composition of the peptide. Moreover, as many $\mathrm{T}$ cell epitopes are mapped using synthetic peptide, they may not represent the naturally processed ligand. Designing MRMs to cover a range of potential flanking residues extending from the core sequence can be used to determine the naturally processed sequence with less material than standard LC-MS/MS. This is particularly true for class II epitopes, since naturally processed forms of these peptides exhibit substantial N- and C-terminal heterogeneity. Recently, we have also described parallel detection and quantitation of both the native antigen and MHC-bound peptides formed from the degradation of this antigen [57]. This study highlights the ability to multiplex analysis to detect multiple MHC-bound peptides and in parallel to sample antigen expression levels, providing a definitive picture of the dynamics of antigen expression and epitope generation. Comparing the absolute levels of peptide-MHC complexes from the same autoantigens presented by the same cell may provide a rationale for selecting peptides that may be poorly tolerogenic.

A. MRM-MS: Fragmentation of selected precursor ions
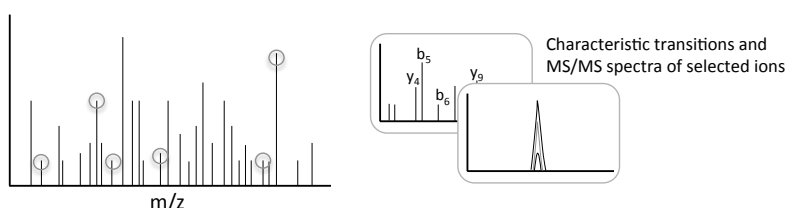

B. LC-MS/MS: Fragmentation of most abundant precursor ions

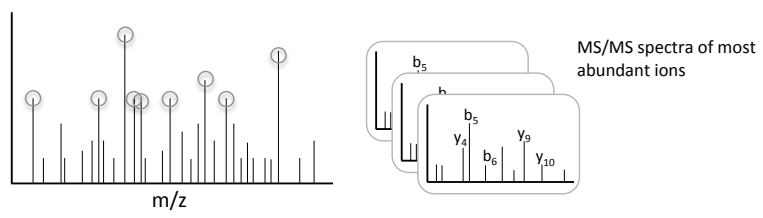

C. SWATH-MS: Fragmentation of all precursor ions

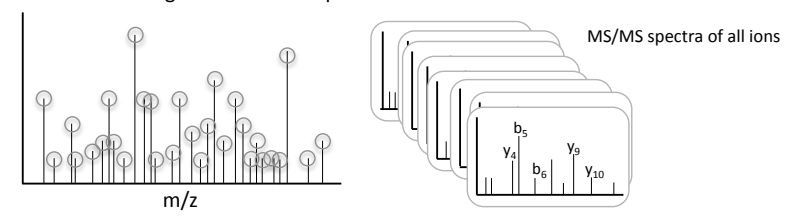

Figure 2: Mass spectrometry approaches for the identification and quantitation of MHC peptides. (A) Multiple reaction monitoring (MRM); during MRM-LCMS, a known peptide(s) of interest is detected based on its precursor mass and characteristic daughter ions generated upon fragmentation. Incorporation of an isotopically labeled internal peptide standard, allows absolute quantitation in the same experiment. (B) LC-MS/MS analysis; only the most abundant precursor ions are selected for fragmentation. Although this technique is not as sensitive as MRM analysis, it does not require any prior knowledge of the peptide of interest, providing a tool for the identification of novel sequences. (C) SWATH-MS; all analytes entering the mass spectrometer are subjected to MS/MS based fragmentation, even those present in low abundance. Postacquisition extraction of peptide precursor mass and fragmentation information allow the detection of peptides of interest.
While MRM analysis allows high sensitivity and the capacity to screen for hundreds to thousands of ligands, the identity of the peptide of interest must be known. Moreover other analytes entering the mass spectrometer are not selected for fragmentation. Although targeted data acquisition facilitates the increase in sensitivity, it does dictate that other analytes of interest cannot be examined post sample acquisition, limiting its use as a discovery tool. A recent addition to the suite of mass spectrometry techniques aims to address this shortfall. SWATH-MS involves data independent acquisition [59], changing the paradigm of how specific peptides are detected and quantitated in mass spectrometry (Figure 2). Instead of fragmenting a set number of analytes entering the mass spectrometer, SWATH-MS allows all analytes to be subjected to MS/MS based fragmentation. This is done by selecting a small packet of analytes within a defined mass window and performing MS/MS on everything before moving on to the next consecutive mass window or SWATH. This provides a comprehensive set of MS/MS data that can be interrogated post-acquisition to extract MS/MS spectral information from each SWATH, for the detection and quantitation of peptides of interest. Thus, unlike MRM analysis, the identity of the peptide of interest need not be known prior to data acquisition.

SWATH differs from standard LC-MS/MS analysis, in that the latter collects fragmentation data for only the most abundant ions entering the mass spectrometer, typically the top 20-30 ions per second. This means that the number of MS/MS spectra collected is capped and many ions with lower abundance will not be selected for fragmentation. During SWATH-MS however, fragmentation data is collected for all ions irrespective of abundance. The data is then interrogated for fragment ions characteristic of a peptide of interest in much the same was as MRM analysis, except that these ions are searched for post-acquisition, rather than using the mass spectrometer to select ions of interest. An example of peptide identification by SWATH is shown in figure 3. Cells over expressing human pre-proinsulin and HLA-A2 were used to identify naturally processed peptides from proinsulin. HLA-A2 was affinity purified from the cells (as described in [42,56,57]) and the associated peptides subjected to LC-MS/MS or SWATH analysis for comparison (manuscript in preparation). During standard LC-MS/MS analysis, the top 30 most abundant ions were selected for fragmentation. Among those peptides sequenced, were two well-known HLA-A2 peptides HLVEALYLV [60-62] and ALWGPDPAAA [63,64]. The spectra obtained for these peptides are shown in figure 3b. During LC-MS/MS analysis; the precursor mass of the peptide is recorded along with the fragment ions generated from that precursor mass, allowing the amino acid sequence of the parent ion to be determined. During SWATH acquisition (Figure 3c), it is not possible to match the precursor ion to the corresponding fragment ions as many ions are subjected to fragmentation simultaneously. Consequently peptides are identified by extracting a set of fragment ions that are characteristic of the peptide of interest. In the case of both peptides, SWATH data was interrogated for the presence of ten fragment ions for each peptide (Figure $3 \mathrm{c}$ iv, shown only for HLVEALYLV). The presence of all of these fragment ions at the same retention time is confirmatory of the parental sequence. The wealth of information that can be obtained from a single experiment is vastly expanded through the use of SWATH analysis. The ability to look for ions post-acquisition when using SWATH-MS means that once collected, the data can be analyzed retrospectively for any newly emerging antigen of interest. This makes it an excellent tool for the identification of novel epitopes and may be particularly relevant when analyzing precious samples such as human islets that are difficult to obtain. 
(A)

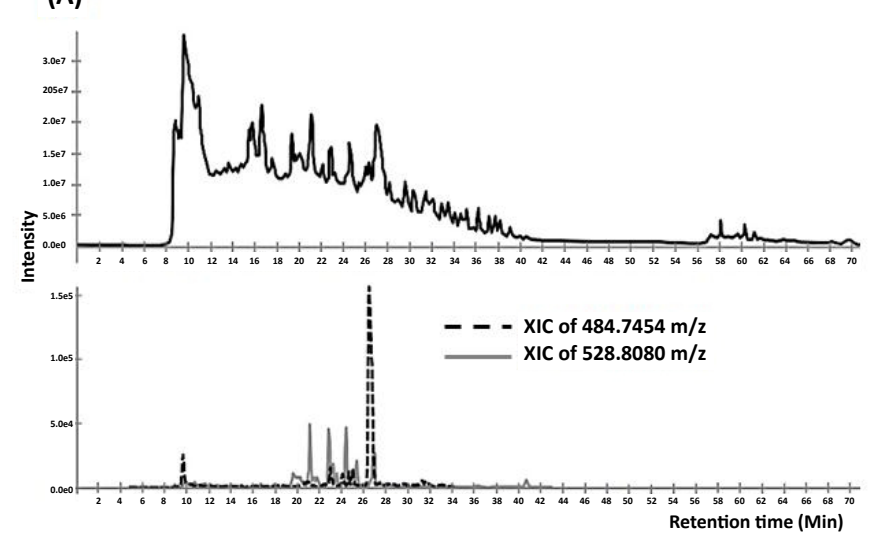

(B)

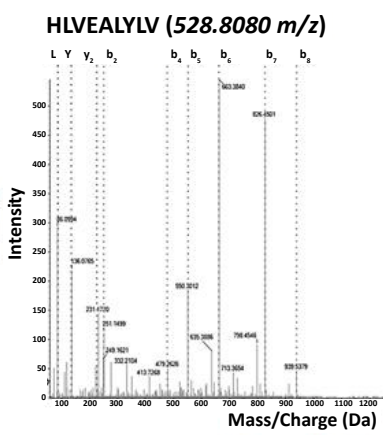

AWLGPDPAAA(484.7454 $\mathrm{m} / \mathrm{z})$

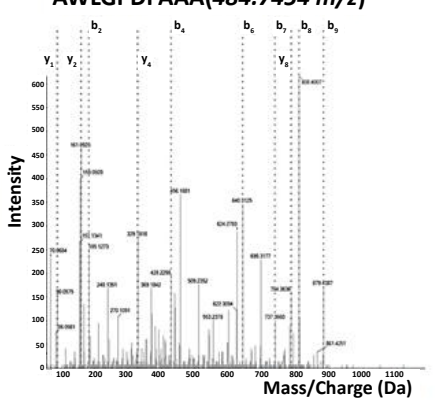

(C) $\mathbf{i}$
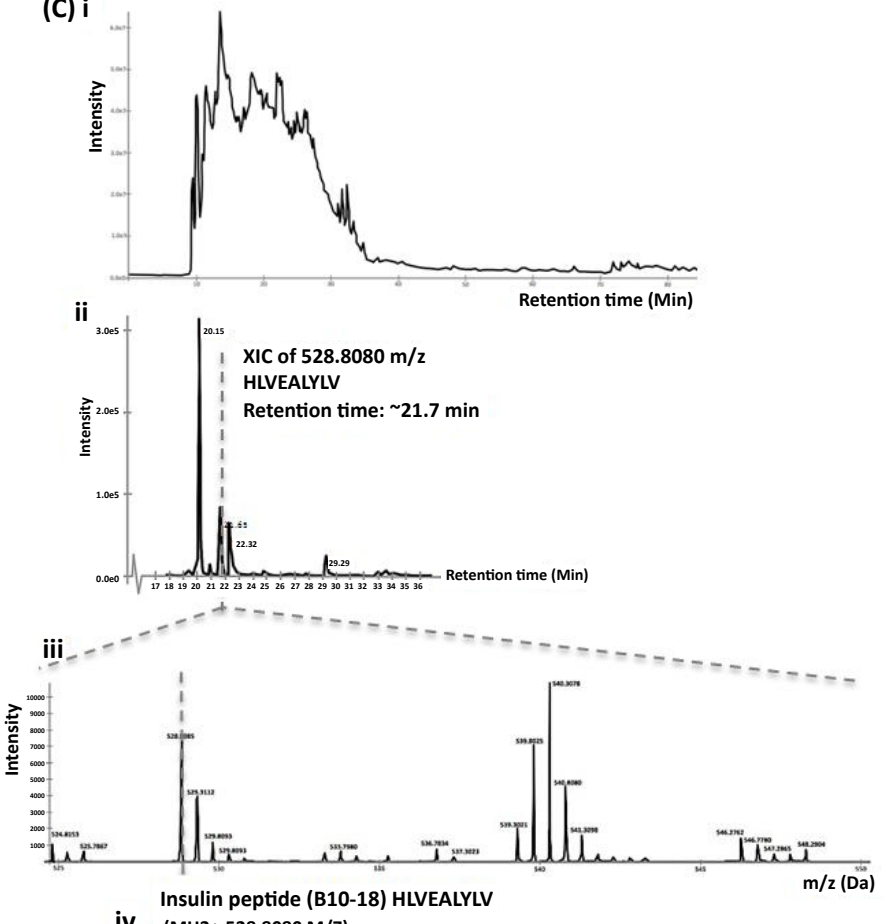

iv $(\mathrm{MH} 2+528.8080 \mathrm{M} / \mathrm{Z})$

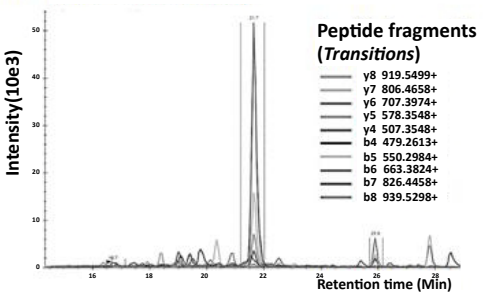

Figure 3: LC-MS/MS and SWATH analysis of two HLA-A2 restricted proinsulin peptides eluted from C1R cells transfected with proinsulin and HLA-A2. (A) Total ion chromatogram (TIC) acquired via information dependent data acquisition (IDA) and the extracted ion chromatograms (XIC) of ions corresponding to and m/z value of $484.7454 \mathrm{Da}$ and $528.8080 \mathrm{Da}$. Shown in (B) are spectra corresponding to these ions identified as insulin B10-18 HLVEALYLV and pre-proinsulin 15-24 AWLGPDPAAA. (C) i depicts the TIC acquired using SWATH-MS and the XIC derived from this SWATH-MS data set corresponding to the HVEALYLV peptide $(528.8080 \mathrm{Da})$ as shown in ii. All ions in the SWATH isolation window of $25 \mathrm{Da}$ width (525-550 Da) containing the B10-18 peptide HLVEALYLV (precursor mass of $528.8080 \mathrm{Da}$ ) across the LC are shown in (C) iii. In (C) iv, the overlapping transitions corresponding to the $y$ - and b-ions of HLVEALYLV at identical retention time (21.7 $\mathrm{min}$ ) are shown confirming detection of this species. For the collection of SWATH data, samples were analyzed by an AB SCIEX TripleTOF® 5600 mass spectrometer by electrospray ionization with the system operating in SWATH ${ }^{\mathrm{TM}}$ acquisition mode. Each cycle consisted of an initial MS1 scan of $100-1800 \mathrm{~m} / \mathrm{z}$, followed by sequential SWATH ${ }^{\mathrm{TM}}$ windows of $25 \mathrm{~m} / \mathrm{z}$ spanning the range of 300-1000 m/z and within these acquiring MS2 data of $100-1800 \mathrm{~m} / \mathrm{z}$. Data were analyzed using the open source software Skyline v1.4. Full scan settings were applied to reflect the SWATH ${ }^{\mathrm{TM}}$ acquisition parameters described above. Transition settings were $y$ and $b$ ions with doubly-charged precursor states and 6 product ions with $\mathrm{m} / \mathrm{z}>$ precursor -2 .

\section{Conclusions}

The emerging role of post-translational modification in the development of disease and the identification of post-translationally modified peptides derived from secretory granule proteins in humans and in models of T1D, supports the notion that altered handling of secretory components is a key contributor to disease. Although this is only one of multiple factors that are no doubt required to manifest autoimmunity in susceptible individuals, the identification of posttranslationally modified and non-classically presented epitopes remains a major goal in T1D research. Recent advances in mass spectrometry will greatly facilitate the identification of beta cell derived T cell ligands. This combined with other "omics" is sure to shed light on the etiology of this debilitating disease and provide new avenues for the ever-growing interest in antigen specific therapies.

\section{Acknowledgements}

This work was supported by a grant to AWP/NLD from JDRF (Project grant 17-2012-134). AWP is a NHMRC SRF.

\section{References}

1. Hirschhorn JN (2003) Genetic epidemiology of type 1 diabetes. Pediatr Diabetes 4: 87-100.

2. Hyttinen V, Kaprio J, Kinnunen L, Koskenvuo M, Tuomilehto J (2003) Genetic liability of type 1 diabetes and the onset age among 22,650 young Finnish twin pairs: a nationwide follow-up study. Diabetes 52: 1052-1055.

3. Musso G, Gambino R, Cassader M (2011) Interactions between gut microbiota and host metabolism predisposing to obesity and diabetes. Annu Rev Med 62 $361-380$.

4. Markle JG, Frank DN, Mortin-Toth S, Robertson CE, Feazel LM, et al. (2013) Sex differences in the gut microbiome drive hormone-dependent regulation of autoimmunity. Science 339: 1084-1088. 
5. Wu HJ, Ivanov II, Darce J, Hattori K, Shima T, et al. (2010) Gut-residing segmented filamentous bacteria drive autoimmune arthritis via $\mathrm{T}$ helper 17 cells. Immunity 32: 815-827.

6. Murri M, Leiva I, Gomez-Zumaquero JM, Tinahones FJ, Cardona F, et al. (2013) Gut microbiota in children with type 1 diabetes differs from that in healthy children: a case-control study. BMC Med 11: 46.

7. King C, Sarvetnick N (2011) The incidence of type-1 diabetes in NOD mice is modulated by restricted flora not germ-free conditions. PLoS One 6: e17049.

8. Ueda H, Howson JM, Esposito L, Heward J, Snook H, et al. (2003) Association of the T-cell regulatory gene CTLA4 with susceptibility to autoimmune disease. Nature 423: 506-511

9. Kristiansen OP, Larsen ZM, Pociot F (2000) CTLA-4 in autoimmune diseases-a general susceptibility gene to autoimmunity? Genes Immun 1: 170-184.

10. Bottini N, Musumeci L, Alonso A, Rahmouni S, Nika K, et al. (2004) A functiona variant of lymphoid tyrosine phosphatase is associated with type I diabetes. Na Genet 36: 337-338.

11. Vella A, Cooper JD, Lowe CE, Walker N, Nutland S, et al. (2005) Localization of a type 1 diabetes locus in the IL2RA/CD25 region by use of tag singlenucleotide polymorphisms. Am J Hum Genet 76: 773-779.

12. Bennett ST, Lucassen AM, Gough SC, Powell EE, Undlien DE, et al. (1995) Susceptibility to human type 1 diabetes at IDDM2 is determined by tandem repeat variation at the insulin gene minisatellite locus. Nat Genet 9: 284-292.

13. Barratt BJ, Payne F, Lowe CE, Hermann R, Healy BC, et al. (2004) Remapping the insulin gene/IDDM2 locus in type 1 diabetes. Diabetes 53: 1884-1889.

14. Maier LM, Wicker LS (2005) Genetic susceptibility to type 1 diabetes. Curr Opin Immunol 17: 601-608.

15. Concannon P, Erlich HA, Julier C, Morahan G, Nerup J, et al. (2005) Type 1 diabetes: evidence for susceptibility loci from four genome-wide linkage scans in 1,435 multiplex families. Diabetes 54: 2995-3001.

16. Noble JA, Erlich HA (2012) Genetics of type 1 diabetes. Cold Spring Harb Perspect Med 2: a007732.

17. Noble JA, Valdes AM, Varney MD, Carlson JA, Moonsamy P, et al. (2010) HLA class I and genetic susceptibility to type 1 diabetes: results from the Type 1 Diabetes Genetics Consortium. Diabetes 59: 2972-2979.

18. Eisenbarth GS (2007) Update in type 1 diabetes. J Clin Endocrinol Metab 92 : 2403-2407.

19. Ziegler AG, Hummel M, Schenker M, Bonifacio E (1999) Autoantibody appearance and risk for development of childhood diabetes in offspring of parents with type 1 diabetes: the 2-year analysis of the German BABYDIAB Study. Diabetes 48: 460-468

20. Bingley PJ (1996) Interactions of age, islet cell antibodies, insulin autoantibodies and first-phase insulin response in predicting risk of progression to IDDM in ICA+ relatives: the ICARUS data set. Islet Cell Antibody Register Users Study. Diabetes 45: 1720-1728.

21. Pugliese A, Zeller M, Fernandez A Jr, Zalcberg LJ, Bartlett RJ, et al. (1997) The insulin gene is transcribed in the human thymus and transcription levels correlated with allelic variation at the INS VNTR-IDDM2 susceptibility locus for type 1 diabetes. Nat Genet 15: 293-297.

22. Vafiadis $P$, Ounissi-Benkalha $H$, Palumbo $M$, Grabs $R$, Rousseau $M$, et al. (2001) Class III alleles of the variable number of tandem repeat insulin polymorphism associated with silencing of thymic insulin predispose to type 1 diabetes. J Clin Endocrinol Metab 86: 3705-3710.

23. French MB, Allison J, Cram DS, Thomas HE, Dempsey-Collier M, et al. (1997) Transgenic expression of mouse proinsulin II prevents diabetes in nonobese diabetic mice. Diabetes 46: 34-39.

24. Chentoufi AA, Polychronakos $C$ (2002) Insulin expression levels in the thymus modulate insulin-specific autoreactive T-cell tolerance: the mechanism by which the IDDM2 locus may predispose to diabetes. Diabetes 51: 1383-1390.

25. Blázquez M, Shennan KI (2000) Basic mechanisms of secretion: sorting into the regulated secretory pathway. Biochem Cell Biol 78: 181-191.

26. Tooze SA (1998) Biogenesis of secretory granules in the trans-Golgi network of neuroendocrine and endocrine cells. Biochim Biophys Acta 1404: 231-244.

27. Colomer V, Kicska GA, Rindler MJ (1996) Secretory granule content proteins and the luminal domains of granule membrane proteins aggregate in vitro at mildly acidic $\mathrm{pH}$. J Biol Chem 271: 48-55.

28. Orci L, Ravazzola M, Amherdt M, Madsen O, Perrelet A, et al. (1986) Conversion of proinsulin to insulin occurs coordinately with acidification of maturing secretory vesicles. J Cell Biol 103: 2273-2281.

29. Stadinski BD, Delong T, Reisdorph N, Reisdorph R, Powell RL, et al. (2010) Chromogranin $A$ is an autoantigen in type 1 diabetes. Nat Immunol 11: 225231.

30. Delong T, Baker RL, Reisdorph N, Reisdorph R, Powell RL, et al. (2011) Islet amyloid polypeptide is a target antigen for diabetogenic CD4+ T cells. Diabetes 60: $2325-2330$

31. Panagiotopoulos C, Qin H, Tan R, Verchere CB (2003) Identification of a betacell-specific HLA class I restricted epitope in type 1 diabetes. Diabetes 52 2647-2651.

32. Standifer NE, Ouyang Q, Panagiotopoulos C, Verchere CB, Tan R, et al. (2006) Identification of Novel HLA-A*0201-restricted epitopes in recent-onset type 1 diabetic subjects and antibody-positive relatives. Diabetes 55: 3061-3067.

33. Gurlo T, Ryazantsev S, Huang CJ, Yeh MW, Reber HA, et al. (2010) Evidence for proteotoxicity in beta cells in type 2 diabetes: toxic islet amyloid polypeptide oligomers form intracellularly in the secretory pathway. Am J Pathol 176: 861 869.

34. Roep BO, Peakman M (2012) Antigen targets of type 1 diabetes autoimmunity. Cold Spring Harb Perspect Med 2: a007781.

35. Di Lorenzo TP, Peakman M, Roep BO (2007) Translational mini-review series on type 1 diabetes: Systematic analysis of $\mathrm{T}$ cell epitopes in autoimmune diabetes. Clin Exp Immunol 148: 1-16.

36. Wenzlau JM, Liu Y, Yu L, Moua O, Fowler KT, et al (2008) A common nonsynonymous single nucleotide polymorphism in the SLC30A8 gene determines ZnT8 autoantibody specificity in type 1 diabetes. Diabetes 57 2693-2697.

37. Kawasaki E, Nakamura K, Kuriya G, Satoh T, Kuwahara H, et al. (2010) Autoantibodies to insulin, insulinoma-associated antigen-2, and zinc transporter 8 improve the prediction of early insulin requirement in adult-onset autoimmune diabetes. J Clin Endocrinol Metab 95: 707-713.

38. Morran MP, Casu A, Arena VC, Pietropaolo S, Zhang YJ, et al. (2010) Humoral autoimmunity against the extracellular domain of the neuroendocrine autoantigen IA-2 heightens the risk of type 1 diabetes. Endocrinology 151 2528-2537.

39. Brunner Y, Couté Y, lezzi M, Foti M, Fukuda M, et al. (2007) Proteomics analysis of insulin secretory granules. Mol Cell Proteomics 6: 1007-1017.

40. Hickey AJ, Bradley JW, Skea GL, Middleditch MJ, Buchanan CM, et al. (2009) Proteins associated with immunopurified granules from a model pancreatic islet beta-cell system: proteomic snapshot of an endocrine secretory granule. J Proteome Res 8: 178-186.

41. Schvartz D, Brunner Y, Couté Y, Foti M, Wollheim CB, et al. (2012) Improved characterization of the insulin secretory granule proteomes. J Proteomics 75 4620-4631.

42. Dudek NL, Tan CT, Gorasia DG, Croft NP, Illing PT, et al. (2012) Constitutive and inflammatory immunopeptidome of pancreatic $\beta$-cells. Diabetes 61: 3018 3025 .

43. Mohan JF, Levisetti MG, Calderon B, Herzog JW, Petzold SJ, et al. (2010) Unique autoreactive $T$ cells recognize insulin peptides generated within the islets of Langerhans in autoimmune diabetes. Nat Immunol 11: 350-354.

44. Mohan JF, Petzold SJ, Unanue ER (2011) Register shifting of an insulin peptide-MHC complex allows diabetogenic T cells to escape thymic deletion. $J$ Exp Med 208: 2375-2383.

45. Michels AW, Ostrov DA, Zhang L, Nakayama M, Fuse M, et al. (2011) Structurebased selection of small molecules to alter allele-specific MHC class II antigen presentation. J Immunol 187: 5921-5930.

46. Illing PT, Vivian JP, Dudek NL, Kostenko L, Chen Z, et al. (2012) Immune self-reactivity triggered by drug-modified HLA-peptide repertoire. Nature 486 554-558.

47. Hetherington S, Hughes AR, Mosteller M, Shortino D, Baker KL, et al. (2002) Genetic variations in HLA-B region and hypersensitivity reactions to abacavir Lancet 359: 1121-1122. 
Citation: Dudek NL, Giam K, Purcell AW (2013) The Use of Proteomics to Dissect the Molecular Specificities of T Cells in Type 1 Diabetes. J Diabetes Metab S12: 006. doi:10.4172/2155-6156.S12-006

48. Mallal S, Nolan D, Witt C, Masel G, Martin AM, et al. (2002) Association between presence of HLA-B*5701, HLA-DR7, and HLA-DQ3 and hypersensitivity to HIV-1 reverse-transcriptase inhibitor abacavir. Lancet 359: 727-732.

49. Kjer-Nielsen L, Patel O, Corbett AJ, Le Nours J, Meehan B, et al. (2012) MR1 presents microbial vitamin B metabolites to MAIT cells. Nature 491: 717-723.

50. Nikoopour E, Sandrock C, Huszarik K, Krougly O, Lee-Chan E, et al. (2011) Cutting edge: vasostatin-1-derived peptide ChgA29-42 is an antigenic epitope of diabetogenic BDC2.5 T cells in nonobese diabetic mice. J Immunol 186 3831-3835.

51. Mannering SI, Harrison LC, Williamson NA, Morris JS, Thearle DJ, et al. (2005) The insulin A-chain epitope recognized by human $T$ cells is posttranslationally modified. J Exp Med 202: 1191-1197.

52. Anderton SM (2004) Post-translational modifications of self antigens: implications for autoimmunity. Curr Opin Immunol 16: 753-758.

53. Petersen J, Purcell AW, Rossjohn J (2009) Post-translationally modified T cell epitopes: immune recognition and immunotherapy. J Mol Med (Berl) 87: 10451051.

54. Lange V, Picotti P, Domon B, Aebersold R (2008) Selected reaction monitoring for quantitative proteomics: a tutorial. Mol Syst Biol 4: 222.

55. Picotti P, Rinner O, Stallmach R, Dautel F, Farrah T, et al. (2010) Highthroughput generation of selected reaction-monitoring assays for proteins and proteomes. Nat Methods 7: 43-46.

56. Tan CT, Croft NP, Dudek NL, Williamson NA, Purcell AW (2011) Direct quantitation of MHC-bound peptide epitopes by selected reaction monitoring. Proteomics 11: 2336-2340.
57. Croft NP, Smith SA, Wong YC, Tan CT, Dudek NL, et al. (2013) Kinetics of antigen expression and epitope presentation during virus infection. PLoS Pathog 9: e1003129.

58. Bozzacco L, Yu H, Zebroski HA, Dengjel J, Deng H, et al. (2011) Mass spectrometry analysis and quantitation of peptides presented on the MHC II molecules of mouse spleen dendritic cells. J Proteome Res 10: 5016-5030.

59. Gillet LC, Navarro P, Tate S, Röst H, Selevsek N, et al. (2012) Targeted data extraction of the MS/MS spectra generated by data-independent acquisition: a new concept for consistent and accurate proteome analysis. Mol Cell Proteomics 11: 0111.016717.

60. Pinkse GG, Tysma OH, Bergen CA, Kester MG, Ossendorp F, et al. (2005) Autoreactive CD8 $T$ cells associated with beta cell destruction in type diabetes. Proc Natl Acad Sci U S A 102: 18425-18430.

61. Hassainya Y, Garcia-Pons F, Kratzer R, Lindo V, Greer F, et al. (2005) Identification of naturally processed HLA-A2--restricted proinsulin epitopes by reverse immunology. Diabetes 54: 2053-2059.

62. Toma A, Haddouk S, Briand JP, Camoin L, Gahery H, et al. (2005) Recognition of a subregion of human proinsulin by class I-restricted T cells in type 1 diabetic patients. Proc Natl Acad Sci U S A 102: 10581-10586.

63. Skowera A, Ellis RJ, Varela-Calviño R, Arif S, Huang GC, et al. (2008) CTLs are targeted to kill beta cells in patients with type 1 diabetes through recognition of a glucose-regulated preproinsulin epitope. J Clin Invest 118: 3390-3402.

64. Chang L, Kjer-Nielsen L, Flynn S, Brooks AG, Mannering SI, et al. (2003) Nove strategy for identification of candidate cytotoxic T-cell epitopes from human preproinsulin. Tissue Antigens 62: 408-417. 